\title{
Recognition of viral RNA stem-loops by the tandem double-stranded RNA binding domains of PKR
}

\author{
EDIS DZANANOVIC, ${ }^{1,4}$ TRUSHAR R. PATEL, ${ }^{1,4}$ SOUMYA DEO, ${ }^{1}$ KEVIN MCELENEY, ${ }^{1,2}$ JÖRG STETEFELD, ${ }^{1,3}$ \\ and SEAN A. MCKENNA ${ }^{1,3,5}$ \\ ${ }^{1}$ Department of Chemistry, University of Manitoba, Winnipeg, Manitoba, R3T 2N2, Canada \\ ${ }^{2}$ Manitoba Institute for Materials, University of Manitoba, Winnipeg, Manitoba, R3T 2N2, Canada \\ ${ }^{3}$ Manitoba Group in Protein Structure and Function, University of Manitoba, Winnipeg, Manitoba, R3T 2N2, Canada
}

\begin{abstract}
In humans, the double-stranded RNA (dsRNA)-activated protein kinase (PKR) is expressed in late stages of the innate immune response to viral infection by the interferon pathway. PKR consists of tandem dsRNA binding motifs (dsRBMs) connected via a flexible linker to a Ser/Thr kinase domain. Upon interaction with viral dsRNA, PKR is converted into a catalytically active enzyme capable of phosphorylating a number of target proteins that often results in host cell translational repression. A number of high-resolution structural studies involving individual dsRBMs from proteins other than PKR have highlighted the key features required for interaction with perfectly duplexed RNA substrates. However, viral dsRNA molecules are highly structured and often contain deviations from perfect A-form RNA helices. By use of small-angle X-ray scattering (SAXS), we present solution conformations of the tandem dsRBMs of PKR in complex with two imperfectly base-paired viral dsRNA stemloops; HIV-1 TAR and adenovirus VA-AS. Both individual components and complexes were purified by size exclusion chromatography and characterized by dynamic light scattering at multiple concentrations to ensure monodispersity. SAXS ab initio solution conformations of the individual components and RNA-protein complexes were determined and highlight the potential of PKR to interact with both stem and loop regions of the RNA. Excellent agreement between experimental and model-based hydrodynamic parameter determination heightens our confidence in the obtained models. Taken together, these data support and provide a framework for the existing biochemical data regarding the tolerance of imperfectly base-paired viral dsRNA by PKR.
\end{abstract}

Keywords: HIV-1 TAR; VA, PKR; protein-RNA interactions; small-angle X-ray scattering

\section{INTRODUCTION}

The interferon response provides a crucial first line of defense against viral pathogens via specific protein production from the interferon-stimulated genes (ISGs) (Malmgaard 2004). These proteins mount a multipronged resistance to viral infection, at least in part by inhibition of host translation in order to slow viral progeny proliferation (Sadler and Williams 2008). Human double-stranded RNA (dsRNA)-activated protein kinase (PKR) is a key ISG that functions in the innate immune response to counteract viral infection via further amplification of the interferon response (Weber et al. 2006; Hovanessian 2007). Latent PKR interacts directly with dsRNA from replication by-products, mRNA transcripts, or the viral genome itself, which enables self-association and ultimately autophosphorylation of two threonine

${ }^{4}$ These authors contributed equally to this work.

${ }^{5}$ Corresponding author

E-mail Sean.McKenna@ad.umanitoba.ca

Article published online ahead of print. Article and publication date are at http://www.rnajournal.org/cgi/doi/10.1261/rna.035931.112. residues that overhang the enzyme's active site (Thomis and Samuel 1993). Autophosphorylated PKR can then target its substrates for phosphorylation, including eukaryotic initiation factor $2 \alpha(\mathrm{eIF} 2 \alpha)$ at Ser51. Phosphorylation of eIF2 $\alpha$ inhibits the guanidine nucleotide exchange activity of the eIF2 heterotrimeric complex, thereby preventing translation initiation (Gale and Katze 1998; Sudhakar et al. 2000). Therefore, dsRNA recognition by $\mathrm{PKR}$ represents an effective means to attenuate both host and viral protein production (Sonenberg and Hinnebusch 2009).

Human PKR is a 551-amino-acid residue enzyme containing three distinct regions, each with specific functional roles in the response to dsRNA. The N-terminal region (residues 1-169) contains tandem dsRNA binding motifs (dsRBMs) that interact with RNA (Fig. 1A). NMR studies of $\mathrm{PKR}_{1-169}$ in isolation revealed that each dsRBM from PKR adopts a canonical fold containing a three-stranded anti-parallel $\beta$-sheet flanked by two $\alpha$-helices with the tandem dsRBMs joined by a 23-amino-acid linker (Nanduri et al. 1998). The C-terminal region encompasses a Ser/Thr kinase domain responsible for target substrate recognition and phosphorylation. Structural 


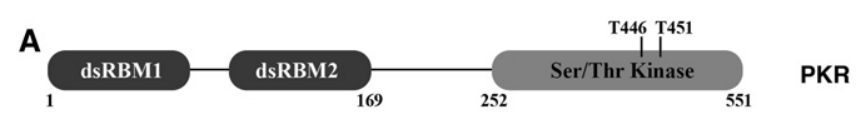

B

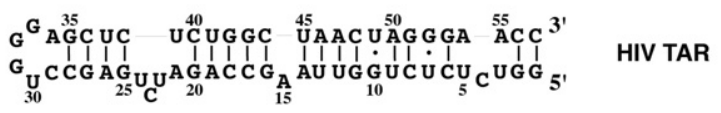

C

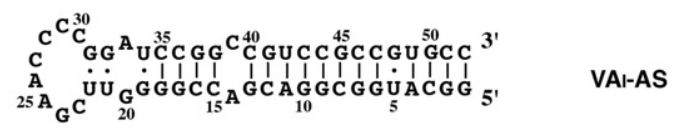

FIGURE 1. Domain organization of PKR and secondary structures of viral dsRNAs. (A) Domain organization of PKR is shown, including the tandem dsRBMs (encompassing residues 1-169), the interdomain linker (residues 170-251), and the Ser/Thr kinase domain (residues 252-551). Key threonine residues in the activation loop that become autophosphorylated upon interaction with dsRNA are also indicated. Secondary structures of HIV-1 TAR $(B)$ and the apical stem-loop of adenovirus $\mathrm{VA}_{\mathrm{I}}\left(\mathrm{VA}_{\mathrm{I}}-\mathrm{AS}\right)(C)$ RNA are shown.

studies on the kinase domain in complex with eIF2a detailed the overall Ser/Thr kinase fold as well as the features required for target substrate interaction (Dar et al. 2005). The dsRNA binding and kinase domains are joined by a third region, an 80-amino-acid flexible interdomain linker implicated in PKR self-association (Lemaire et al. 2005; VanOudenhove et al. 2009). Previous studies have suggested significant flexibility in the two linkers (one between the dsRBMs, the other between the dsRBMs and kinase domains), allowing for two distinct conformations to be observed: an extended "open" conformation where dsRBMs and kinase domains are not in contact, and a collapsed "closed" conformation (Carpick et al. 1997; Gabel et al. 2006; Lemaire et al. 2006; McKenna et al. 2007; VanOudenhove et al. 2009). Together, the data suggest a direct communication between domains that allows propagation of the activation signal from the dsRNA binding to the kinase domain via the interdomain linker.

Binding of dsRNA to dsRBMs significantly enhances the kinase activity of PKR (Thomis and Samuel 1993). The molecular basis for the interaction has been studied extensively with a variety of synthetic and biological dsRNA molecules, although no high-resolution structure of PKR in complex with RNA exists. Productive interaction requires residues from both dsRBM1 and -2 as well as the linker that joins them (Kim et al. 2006). One of the most unique features of PKR is its selectivity for dsRNA: Single-stranded polynucleotides, dsDNA, and DNA-RNA hybrids are not capable of high-affinity interaction (Gale and Katze 1998). Structures of a single dsRBM from proteins other than PKR in complex with perfectly duplexed dsRNA indicate that approximately 1.5 turns ( $\sim 16 \mathrm{bp}$ ) of the A-form RNA helix comprising consecutive minor-major-minor grooves are recognized and that contacts are mediated primarily through the 2'-hydroxyl groups of the ribose sugar, explaining the observed selectivity (Bycroft et al. 1995; Kharrat et al. 1995; Ryter and Schultz
1998; Ramos et al. 2000; Gan et al. 2006; Stefl et al. 2010). In addition to a minimum length requirement ( $\sim 16 \mathrm{bp})$, specific structural (bulges, loops, etc.) and nucleotide modifications (i.e., $5^{\prime}$-phosphorylation state) have been observed to be accommodated by PKR and, in some cases, significantly affect both the affinity for and activation of PKR (Bevilacqua and Cech 1996; Kim et al. 2006; McKenna et al. 2006; Puthenveetil et al. 2006; Nallagatla et al. 2007; Nallagatla and Bevilacqua 2008). As there is scant structural information about imperfectly duplexed RNA in complex with PKR, a detailed understanding of how PKR accommodates these deviations remains an unanswered question.

A well-characterized viral dsRNA regulator of PKR is the HIV-1 transactivation response (TAR) element, an RNA stem-loop structure spanning nucleotides +1 to +59 of the newly synthesized viral mRNA (Berkhout et al. 1989). TAR adopts an A-form RNA helix with distortions including a trinucleotide bulge and hexaloop (Fig. 1B; Puglisi et al. 1992; Aboul-ela et al. 1996). HIV-infected cells treated with interferon demonstrate a decreased production of HIV proteins, as well as HIV particles (Benkirane et al. 1997). The interferon-mediated response is ascribed to the activity of PKR in lymphocytes as transduction of PKR into T-cell progeny protects cells from HIV-1 infection and severely inhibits HIV-1 replication rates in infected cells (Dimitrova et al. 2005). An important link between host innate immune response and HIV-1 infection appears to be mediated by PKR through a specific interaction with HIV-1 TAR RNA. HIV-1 TAR RNA has been established as a regulator of PKR kinase activation, where high-affinity interaction requires the presence of $16 \mathrm{bp}$ proximal to the loop as well as both the bulge and hexaloop (SenGupta and Silverman 1989; Gunnery et al. 1992; Maitra et al. 1994; Kim et al. 2006). Given that each individual dsRBM requires $\sim 15$ bp for interaction, it is unclear how the tandem dsRBM domains of PKR are interacting with TAR RNA. A recent study has suggested that defects (i.e., bulge or hexaloop) serve as anti-determinants to PKR binding and activation and that TAR unwinding and dimerization represents the activating species (Heinicke et al. 2009). However, the biological basis for TAR dimerization remains unresolved at present.

High-resolution information on the tandem dsRBMs of PKR in complex with dsRNA complex has been difficult to obtain, likely due to the established flexibility of both the linker between dsRBM1 and -2 and the inherent flexibility of stem-loop RNA structures. Here we present the solution conformation of tandem dsRBMs of PKR in complex with an imperfectly base-paired viral dsRNA using small-angle $\mathrm{X}$-ray scattering (SAXS). Ab initio analysis of $\mathrm{PKR}_{1-169}$, HIV-1 TAR, and the protein-RNA complex were performed to investigate how each dsRBM orients and interacts with TAR RNA. Dynamic light scattering (DLS) was employed to (1) investigate the homogeneity of macromolecules at various concentrations, (2) measure the hydrodynamic radius of individual macromolecules as well as their complexes, and 
(3) compare the calculated values from SAXS models with experimentally determined values. This experimental approach was repeated using a second model RNA ligand, the apical stem of adenovirus $\mathrm{VA}_{\mathrm{I}} \mathrm{RNA}$, in order to confirm the validity of the results with a second established binding partner of PKR. Together these results provide a plausible framework for the recognition of short, imperfectly basepaired RNA ligands by the tandem dsRBMs of PKR and highlight the effectiveness of SAXS approaches for systems with highly flexible components.

\section{RESULTS}

\section{RNA-protein complex purification and characterization}

In perfectly duplexed dsRNA, the tandem dsRBMs of PKR require a minimum of $15 \mathrm{bp}$ ( 1.5 turns of the A-RNA helix) for interaction, and yet based on existing structures, it would be expected that each dsRBM would require the entire $15 \mathrm{bp}$. Additionally, PKR is capable of tolerating deviations from perfect duplexes, including bulges, internal loops, and loops for high-affinity binding. In order to study the structural basis for these interactions, we sought to determine the solution conformation of two dsRNA-PKR complexes by SAXS. Complexes were assembled with purified recombinant $\mathrm{PKR}_{1-169}$, which contains both dsRBM1 and -2 and retains identical binding affinity to the full-length PKR (Fig. 2). DLS experiments were performed to study homogeneity of all macromolecules and to determine the hydrodynamic radius $\left(r_{H}\right)$ of each species being studied at multiple concentrations. $\mathrm{PKR}_{1-169}$ displays a narrow distribution of hydrodynamic radii at all concentrations examined, consistent with a monodisperse sample $(2.80 \pm 0.10 \mathrm{~nm})$ (Fig. 3A). A linear distribution of $r_{H}$ over multiple concentrations (2.50-6.50 $\mathrm{mg} / \mathrm{mL}$ ) was observed, suggesting minimal concentration dependence on the Stokes radius (Fig. 3B).

RNA model ligands were selected based on (1) their high affinity $(\sim 100 \mathrm{nM})$ for $\mathrm{PKR}_{1-169}$ (Fig. 2A), (2) their ability to stimulate autophosphorylation and kinase activity of PKR, and (3) the fact that they are short, imperfectly basepaired dsRNA stem-loops. Based on these criteria, we selected HIV-1 TAR RNA (57 nucleotides [nt]) and the apical stem of adenovirus $\mathrm{VA}_{\mathrm{I}}$ RNA (52 nt) (Fig. 1B). Both RNAs were in vitro transcribed from linearized template, purified by size exclusion chromatography, and subjected to native gel electrophoresis. Both TAR (Fig. 2A, lane 1) and apical stemloop of adenovirus $\mathrm{VA}_{\mathrm{I}}\left(\mathrm{VA}_{\mathrm{I}}-\mathrm{AS}\right.$ ) (data not shown) behave as a single species based on this analysis. DLS confirmed the $r_{H}$ value consistent with monomeric TAR $(2.7 \pm 0.2$ $\mathrm{nm}$ ) over the concentration range examined, indicating minimal concentration dependence on Stokes radius, thus excluding the possibility of presence of aggregation (Fig. 3C). Identical observations were made for $\mathrm{VA}_{\mathrm{I}}$-AS $\left(r_{H}=2.58 \pm\right.$ $0.05 \mathrm{~nm}$ ) that has similar size to that of TAR, suggesting
A

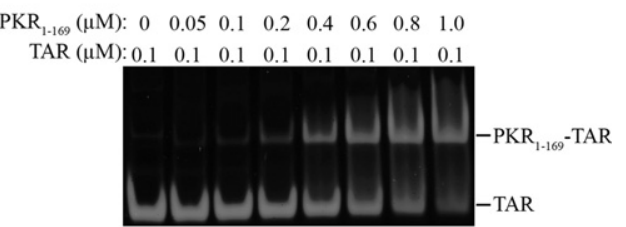

B

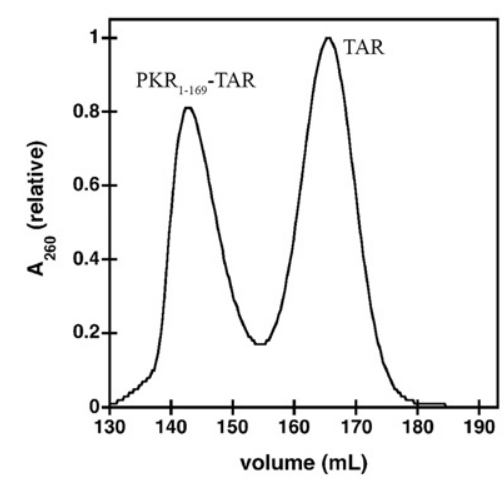

C

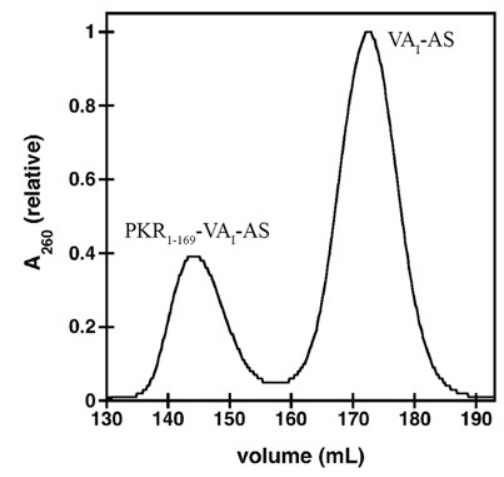

FIGURE 2. RNA-protein complex purification by size exclusion

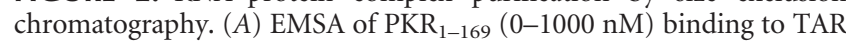
RNA (100 nM) confirming the formation of a single complex. HiLoad 26/60 Superdex 75 size exclusion chromatography purification of the $\mathrm{PKR}_{1-169}$-TAR complex $(B)$ and the $\mathrm{PKR}_{1-169}-\mathrm{VA}_{\mathrm{I}}$-AS complex $(C)$. Concentration of elution fractions was monitored by in-line spectrophotometric detection at 260 and $280 \mathrm{~nm}$ simultaneously.

that both RNA have a similar shape in solution as $r_{H}$ depends on size and shape of macromolecules (Fig. 3D). The determined hydrodynamic radii of the RNA species being studied are within error of each other, consistent with their size exclusion chromatography elution profiles.

Complexes containing $\mathrm{PKR}_{1-169}$ and either TAR or $\mathrm{VA}_{\mathrm{I}}-\mathrm{AS}$ were assembled in the presence of excess RNA to minimize nonspecific protein binding and maximize 1:1 stoichiometry. At low concentrations, electrophoretic mobility shift assays (EMSAs) confirm the emergence of a single higher-molecular-weight species upon incubation of TAR with increasing concentrations of $\mathrm{PKR}_{1-169}$ (Fig. 2A). Identical results were obtained with $\mathrm{VA}_{\mathrm{I}}$-AS-containing complex (data not shown). Complexes were then assembled at high concentration ( $\mu \mathrm{M}$ range) and purified away from free RNA by size exclusion chromatography (Fig. 2B,C). Given that solution 
A

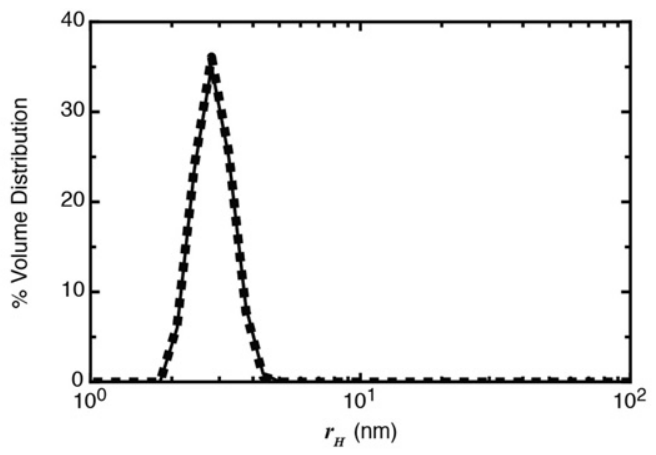

C

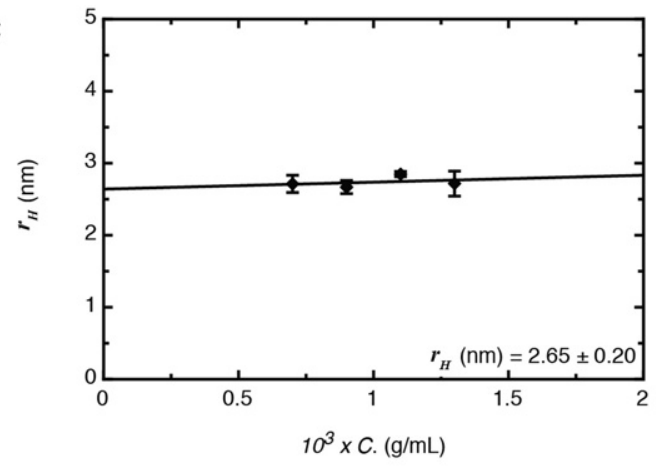

E

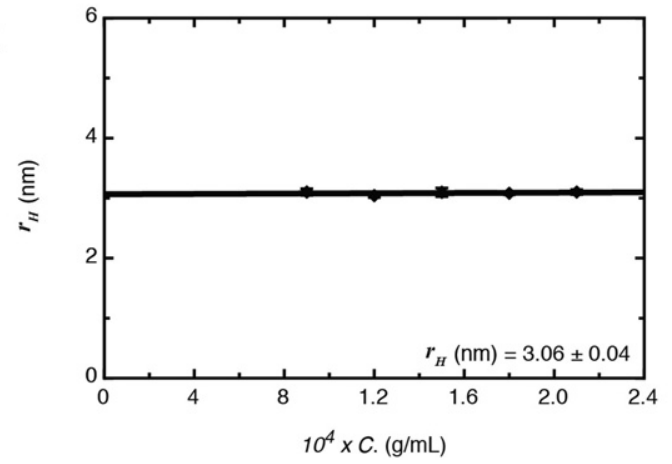

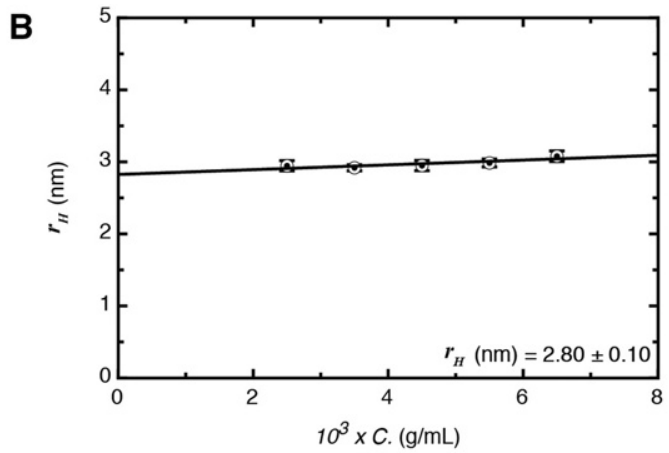
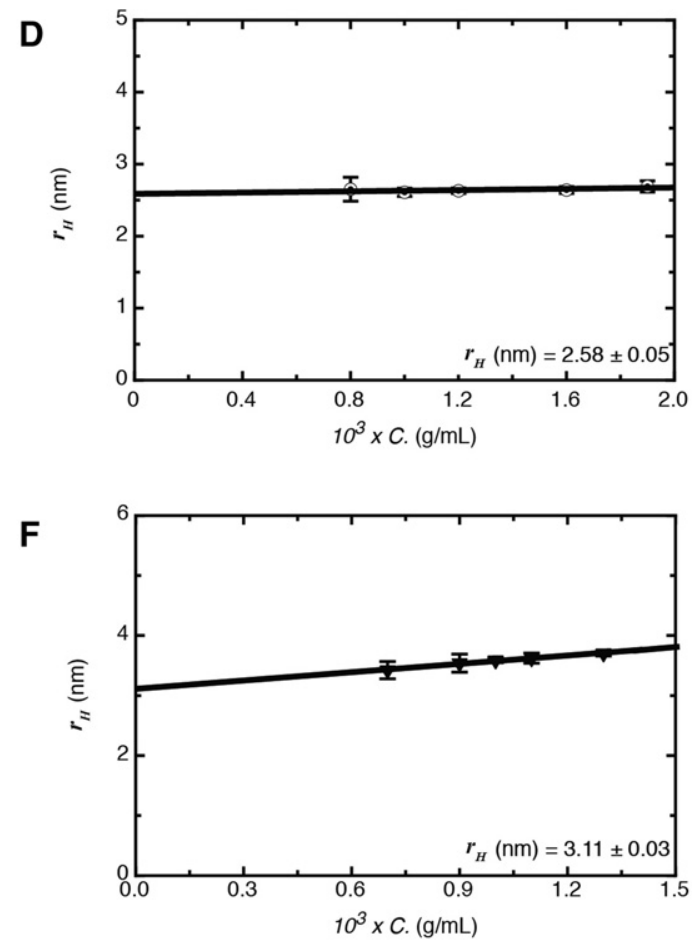

FIGURE 3. Monodispersity of individual components and RNA-protein complexes. (A) Representative DLS profile of PKR $1-169$ at $3.50 \mathrm{mg} / \mathrm{mL}$, before (solid line) and after (dotted line) SAXS data collection. The curves are superimposable, indicating no sample deterioration. The concentration dependence of the hydrodynamic radius $\left(r_{H}\right)$ was determined by DLS for $(B) \mathrm{PKR}_{1-169},(C)$ TAR, $(D) \mathrm{VA}_{\mathrm{I}}-\mathrm{AS},(E)$ the $\mathrm{PKR}_{1-169}-\mathrm{TAR}$ complex, and $(F)$ the $\mathrm{PKR}_{1-169}-\mathrm{VA}_{\mathrm{I}}-\mathrm{AS}$ complex. Each experiment was performed in quadruplicate; error, SD from the mean.

conformation data quality by SAXS is sensitive to sample heterogeneity, this step is essential to ensure the removal of uncomplexed dsRNA. The elution profile for both complexes shows two distinct peaks: a higher-molecular-weight peak corresponding to RNA-protein complex followed by a lower-molecular-weight peak corresponding to free RNA.

The DLS profiles of complexes are also linear with respect to increasing concentration, showing no signs of aggregation across the concentration range at which the experiments were performed (Fig. 3E,F). $\mathrm{PKR}_{1-169}$ in complex with either TAR $\left(r_{H}=3.06 \pm 0.04 \mathrm{~nm}\right)$ or $\mathrm{VA}_{\mathrm{I}}-\mathrm{AS} \operatorname{TAR}\left(r_{H}=3.11 \pm 0.03 \mathrm{~nm}\right)$ is monodisperse and within error demonstrates similar $r_{H}$ values, consistent with their elution profiles from size exclusion chromatography. As expected, an increase in $r_{H}$ is observed in the complex compared with the individual components, although relative to the largest component $\left(\mathrm{PKR}_{1-169}\right)$, these increases were relatively moderate for both TAR (9\%) and $\mathrm{VA}_{\mathrm{I}}-\mathrm{AS}(11 \%)$. Taken together, these results confirm complex homogeneity and suggest a sideby-side orientation of both RNA-protein complexes.

\section{The dsRNA binding domain of PKR adopts an extended conformation in solution}

To understand the behavior of dsRNA-PKR ${ }_{1-169}$ complexes in solution, we first studied the individual protein and RNA components in solution using SAXS. As our starting point, we first examined $\mathrm{PKR}_{1-169}$ as the high-resolution 
structure of this protein construct has already been determined in solution (Nanduri et al. 1998) and will serve to validate the quality of SAXS results. SAXS data collected at multiple concentrations were merged to generate a single scattering profile for $\mathrm{PKR}_{1-169}$ for further data analysis (Fig. 4A, red circles). First, the scattering data were used to generate a distance distribution plot that presents a frequency histogram of all observed electron pairs in the molecule, enabling determination of key parameters, including the radius of gyration $\left(r_{G}\right)$ and the maximum particle dimension $\left(D_{\max }\right)$ using the program GNOM (Svergun 1992). A skewed bellshaped distance distribution function was observed typical for elongated molecules that may contain flexible regions (Fig. 4B, red circles). The experimentally calculated $r_{G}$ and $D_{\max }$ for $\mathrm{PKR}_{1-169}$ are $2.53 \pm 0.04 \mathrm{~nm}$ and $9.0 \mathrm{~nm}$, respectively (Table 1). Based on the scattering data, multiple ab initio solution conformations for $\mathrm{PKR}_{1-169}$ were generated using the program DAMMIF (Franke and Svergun 2009) and superimposed using DAMAVER (Volkov and Svergun 2003) to generate an average surface envelope of the protein (Fig. 5A). The molecule adopts an extended structure that appears to orient the individual dsRBMs at opposite ends joined by the linker. However, the relatively uniform broadness of the entire molecule (including both the dsRBMs and linker) is consistent with the flexible nature of the linker. The $\chi$-value
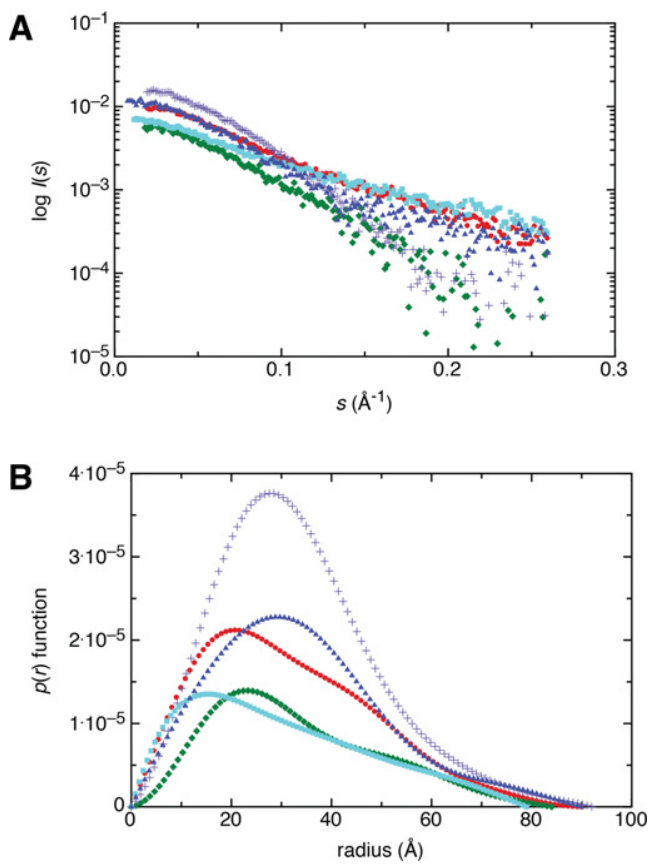

FIGURE 4. Characterization of complexes by SAXS. (A) SAXS scattering profiles for $\mathrm{PKR}_{1-169}$ (red circles), TAR (green diamonds), $\mathrm{VA}_{\mathrm{I}}$-AS (cyan squares), the $\mathrm{PKR}_{1-169}-\mathrm{TAR}$ complex (purple plus signs), and the $\mathrm{PKR}_{1-169}-\mathrm{VA}_{\mathrm{I}}$-AS complex (blue triangles). Each data point represents the merged raw data from multiple sample concentrations. (B) Dependence of the pair distribution function upon particle radius for each of the samples outlined in $A$. obtained for individual ab initio models was approximately 0.9 , illustrating an excellent agreement between experimental data and that obtained from the ab initio calculation. Furthermore, the normalized spatial discrepancy (NSD) parameter of $0.80 \pm 0.04$ among the ab initio models generated to create the average model indicates very little difference between individual $\mathrm{PKR}_{1-169}$ models. In order to validate the ab initio calculations, the program HYDROPRO (de la Torre et al. 2000) was employed to calculated hydrodynamic parameters. The $r_{G}$ of $2.62 \pm 0.02 \mathrm{~nm}, D_{\max }$ of $9.5 \pm 0.05 \mathrm{~nm}$, and $r_{H}$ of $2.76 \pm 0.06 \mathrm{~nm}$ are in good agreement with experimentally calculated hydrodynamic properties (Table 1). Identical DLS results were obtained after SAXS data collection, confirming absence of any radiation damage to the sample after exposure to X-rays (Fig. 3A).

To validate our ab initio modeling approach and to determine the orientation of individual dsRBMs within the solution conformation, we took advantage of the existing high-resolution solution structure of $\mathrm{PKR}_{1-169}$ (Protein Data Bank [PDB] identification 1QU6) (Nanduri et al. 1998). This was accomplished by employing the program BUNCH (Petoukhov and Svergun 2005), which is able to utilize high-resolution information and identify optimal positions and orientations of individual domains (dsRBMs) for which the high-resolution structural information is available, as well as place dummy residues for regions where the highresolution information is missing. In order to prevent model bias, the linker was severed in the center such that each dsRBM could rotate freely. All the structures calculated were nearly identical to each other as well as to the determined ab initio models that do not incorporate information from high-resolution data (Fig. 5B). Overall, the ab initio model comfortably accommodates each dsRBM and strongly suggests that the linker can adopt a number of different configurations. BUNCH data analysis also suggests that dsRBM1 is positioned into the shorter arm while dsRBM2 is positioned in the longer arm of the SAXS model. The hydrodynamic parameters calculated from ab initio models as well as for three-dimensional structures from $\mathrm{BUNCH}$ are not only nearly identical but also agree very well with those parameters determined experimentally, thereby validating our modeling approach (Table 1).

\section{Solution conformation of HIV-1 TAR and adenovirus VA -AS RNA}

SAXS data for TAR and $\mathrm{VA}_{\mathrm{I}}$-AS were collected at multiple concentrations and merged to generate their respective scattering profiles (Fig. 4A). The resultant distance distribution functions for both TAR and $\mathrm{VA}_{\mathrm{I}}$-AS demonstrate a bellshaped curve with an extended tail that is consistent with an elongated stem-loop conformation (Fig. 4B). For TAR, the experimentally determined values of $r_{G}$ and $D_{\max }$ are $2.60 \pm 0.05 \mathrm{~nm}$ and $8.4 \mathrm{~nm}$, respectively. The pair-distance distribution plot was utilized for ab initio analysis to obtain 


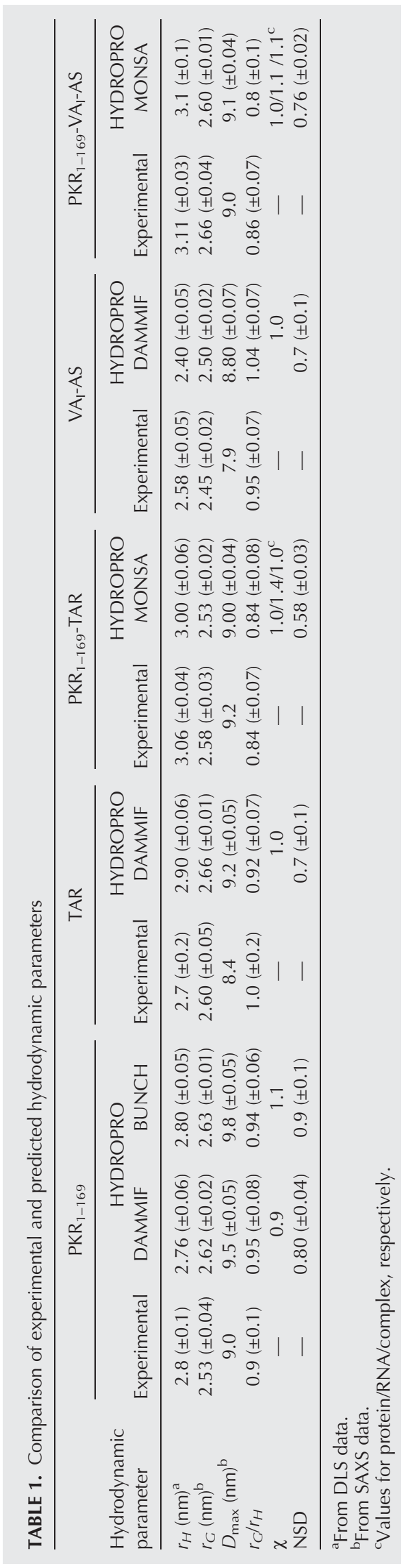


A

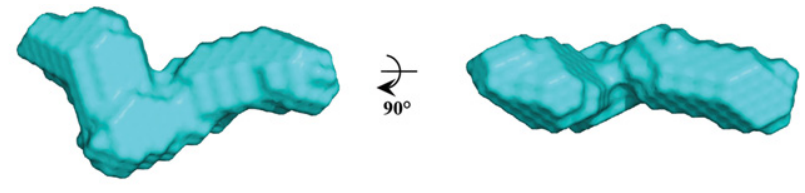

B
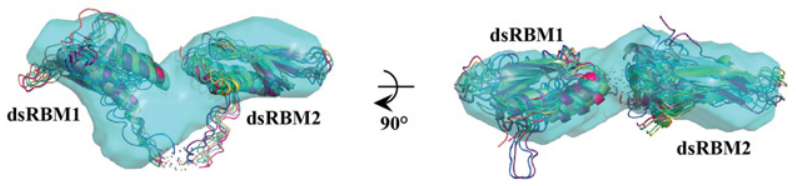

C
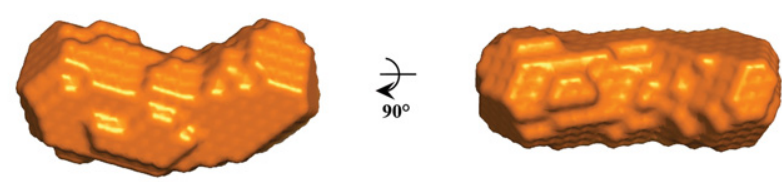

D

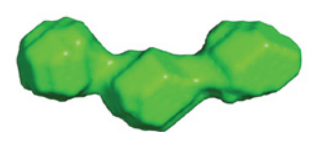

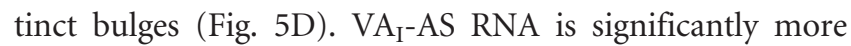
compact than TAR, which suggests that $\mathrm{VA}_{\mathrm{I}}$-AS adopts a more rigid conformation in solution than TAR. The slightly smaller $r_{G}$ and $D_{\max }$ values may be due to the smaller RNA size $(52$ vs. $57 \mathrm{nt})$. The $r_{H}(2.40 \pm 0.05 \mathrm{~nm}), r_{G}(2.50 \pm 0.07$ $\mathrm{nm})$, and $D_{\max }(8.80 \pm 0.07 \mathrm{~nm})$ values for the $\mathrm{VA}_{\mathrm{I}}-\mathrm{AS}$ models were calculated using HYDROPRO and are consistent with experimentally determined values (Table 1). DLS results before and after data acquisition were identical, confirming that no significant sample deterioration due to radiation damage occurred (data not shown).

\section{Solution conformation of the PKR $_{1-169}$-TAR complex}

To determine the molecular basis for the interaction between PKR and TAR RNA, we subjected purified complex to SAXS analysis. The merged scattering data from multiple concentrations of complex were used to generate the distance distribution function, which indicates an extended structure with corresponding $r_{G}(2.58 \pm 0.03 \mathrm{~nm})$ and $D_{\max }(9.2 \mathrm{~nm})$ values (Fig. 4A,B). The experimentally determined $D_{\max }$ for the complex is within error of each of the individual RNA and protein components, consistent with a side-by-side as opposed to end-to-end orientation of the complex. Individual ab initio solution conformations of the $\mathrm{PKR}_{1-169}-\mathrm{TAR}$ complex were determined using the MONSA software suite, which exploits the differential scattering intensity of RNA and protein components to allow visualization of each molecule in the complex. The best-fit model based on comparison with experimental data is shown in Figure 6A. The RNAprotein interface curves along the length of the extended complex structure, with both dsRBMs and the linker region between them located in close proximity to the RNA. As opposed to the free TAR RNA model, the RNA stem-loop is clearly visualized upon complex formation with $\mathrm{PKR}_{1-169}$, and both the loop and stem regions of the RNA are spatially close to PKR based on the MONSA analysis. The overall solution conformation of $\mathrm{PKR}_{1-169}$ is similar to that of the free protein, and therefore, it appears as though dsRBM1 is oriented toward the loop of TAR, with the linker and dsRBM2 primarily mediating the interaction with the stem region of the RNA. Finally, the solution conformation is consistent with 1:1 stoichiometry, as other stoichiometries tested were unable to sustain reasonable fits to the raw data. For comparison, the average solution conformation from the individual MONSA fits is significantly less information-rich, yet defines a disc-shaped surface envelope (Fig. $7 \mathrm{~A})$. The determined $\chi$-values of approximately 1.0 and a NSD value of $0.58 \pm 0.03$ for the complex indicates a quality fit between the calculated individual solution structures and the raw scattering data. Model-based parameter determinations are in good agreement with experimentally determined values, including the SAXS model-based and DLS-determined $r_{H}$ values (Table 1). 
A
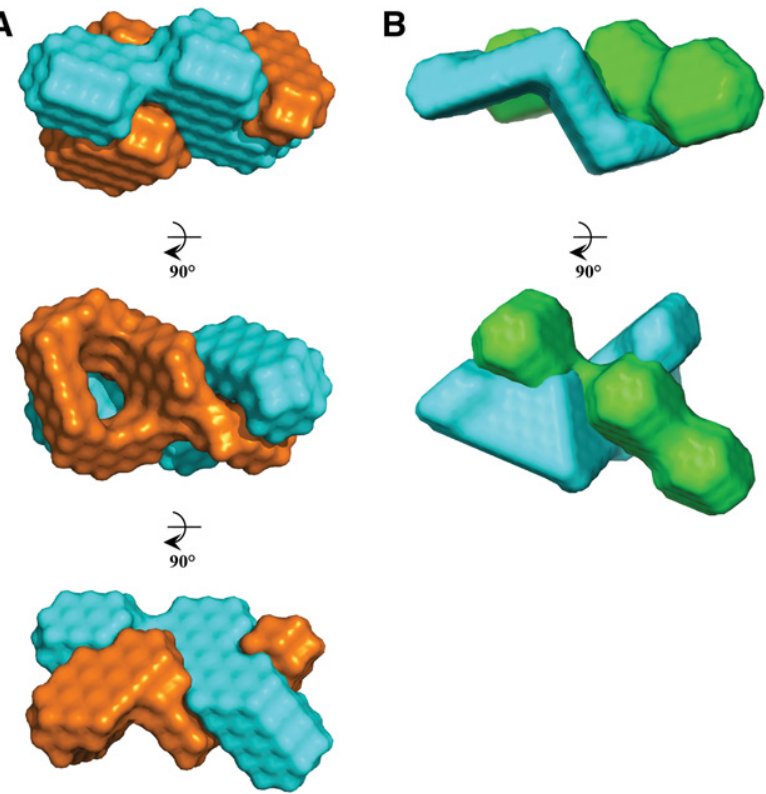

FIGURE 6. Modeling of complexes with MONSA. MONSA uses scattering information for individual components and complex to resolve the structure of complex. (A) Best fit ab initio model of $\mathrm{PKR}_{1-169}-\mathrm{TAR}$ complex where individual components can be visualized $\left(\mathrm{PKR}_{1-169}\right.$ in cyan, TAR in orange). (B) Best fit solution ab initio model of $\mathrm{PKR}_{1-169}-\mathrm{VA}_{\mathrm{I}}$-AS ( $\mathrm{PKR}_{1-169}$ in cyan, $\mathrm{VA}_{\mathrm{I}}$-AS in green).

\section{$\mathrm{VA}_{\mathrm{I}}$-AS and TAR adopt similar overall conformations in complex with PKR $_{1-169}$}

Finally, we performed SAXS experiments on purified $\mathrm{PKR}_{1-169}-\mathrm{VA}_{\mathrm{I}}$-AS to determine whether a similar solution conformation could be observed to the $\mathrm{PKR}_{1-169}$-TAR complex. Experimental hydrodynamic parameters based on the distance distribution function calculated from the raw scattering data are within error of those determined for the TAR-containing complex (Fig. 4; Table 1). The overall topology of individual surface conformation models presents an extended structure in which, again, the dsRBMs of PKR track the length of the $\mathrm{VA}_{\mathrm{I}}$-AS RNA molecule (Fig. 6B). The entire length of the $\mathrm{PKR}_{1-169}$ protein mediates the interaction, presumably via the dsRBMs and linker joining them. Unlike in the TAR-containing complex, the loop region of the $\mathrm{VA}_{\mathrm{I}}$-AS RNA was not pronounced, and no significant conformation change is observed in the RNA molecule upon protein binding. However, the overall disc-shaped topology is similar between the two complexes, as illustrated by the comparison of the solution conformations (Fig. 7B). As with all other molecules examined by SAXS, the model validation parameters $(\chi ;$ NSD) and hydrodynamic parameters $\left(r_{H} ; r_{G} ; D_{\max }\right)$ are also consistent with an accurate model determination (Table 1).

\section{DISCUSSION}

PKR belongs to a large family of dsRBM-containing proteins that vary in terms of the number of dsRBMs they contain

(typically one to five) and their cellular function (Saunders and Barber 2003). The structure of the individual dsRBMs from proteins other than PKR in complex with synthetic RNA duplexes suggest that the A-RNA helix is recognized in a sequence-independent manner via the $2^{\prime}$-hydroxyl groups of the ribose sugar in the minor grooves and nonbridging oxygen residues of the phosphodiester backbone in the intervening major groove (Bycroft et al. 1995; Kharrat et al. 1995; Ryter and Schultz 1998; Ramos et al. 2000; Gan et al. 2006). To date, no high-resolution structure of the dsRBMs of PKR in complex with either synthetic or natural ligands exists, nor does a clear understanding exist of how PKR is capable of interacting with imperfectly duplexed RNA ligands. Therefore we sought to structurally characterize the interaction between the tandem dsRBMs of PKR and two viral dsRNA ligands, HIV-1 TAR and a stem-loop form adenovirus $\mathrm{VA}_{\mathrm{I}}\left(\mathrm{VA}_{\mathrm{I}}\right.$-AS) (Fig. 1).

We chose to examine the conformation of individual components and complexes by SAXS, a solution-based structural technique that allows low-resolution determination of molecular shape and, importantly, can accommodate systems that are dynamic. While SAXS experiments directly determine $r_{G}$ ad $D_{\max }$ values, solution conformation determination requires additional assumptions that make model validation extremely important. All protein, RNA, and complexes were purified by size exclusion chromatography to remove heterogeneity and were confirmed monodisperse by DLS
A
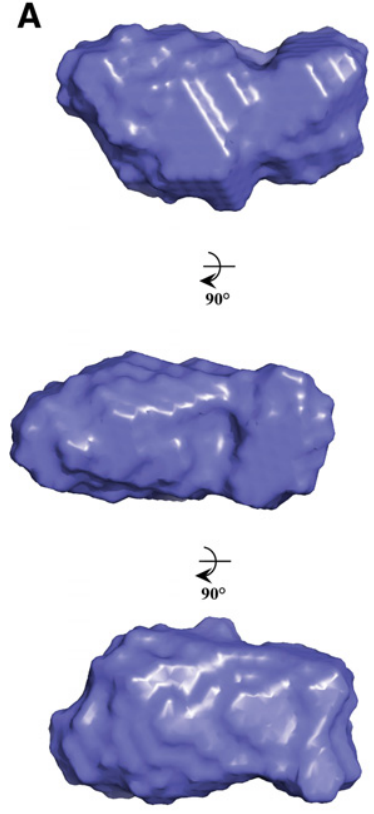

B
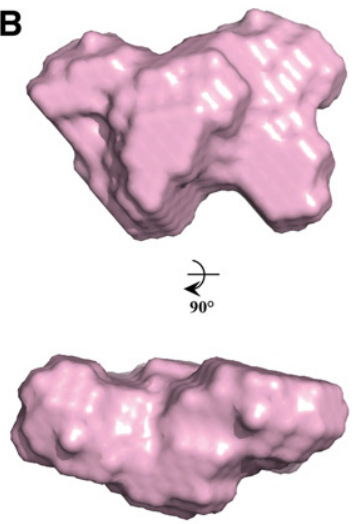

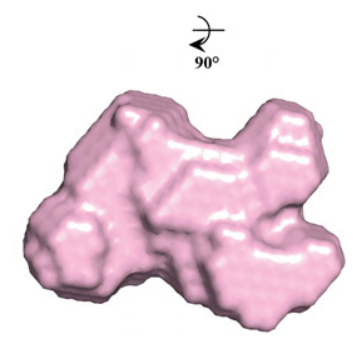

FIGURE 7. Averaged MONSA models of complexes. (A) Averaged ab initio model of $\mathrm{PKR}_{1-169}$-TAR (top left) and its $90^{\circ}$ rotation (bottom left) around its major axis. (B) Averaged solution ab initio model of $\mathrm{PKR}_{1-169}-\mathrm{VA}_{\mathrm{I}}$-AS (top right) and its $90^{\circ}$ rotation (bottom right) around its major axis. 
prior to SAXS experiments (Figs. 2, 3). All samples demonstrated a no dependence of $r_{H}$ on sample concentration, confirming their suitability for SAXS experiments (Fig. 3). Confidence statistics ( $\chi \sim 1$ in all cases) on individual models indicate an excellent fit with the raw scattering data. NSD values (less than 0.9 in all cases) confirm that the individual models share similar structural features. Model-based calculation of hydrodynamic parameters are within error of the experimentally determined values and, importantly, are cross-validated with the independently determined $r_{H}$ values from DLS experiments. DLS experiments performed after SAXS data collection for each sample demonstrated absence of any sample degradation due to radiation damage. Finally, by using BUNCH modeling with the known NMR solution structure of $\mathrm{PKR}_{1-169}$, it was possible to recapitulate the determined SAXS model and potentially orient the individual dsRBMs to specific regions of the model. Taken together, these results give us high confidence in the determined solution conformations.

Models of RNA-protein complexes were determined using MONSA, software that ultimately allows for the separate visualization of both protein and RNA components. The experimentally determined solution structure of TAR in complex with the tandem dsRBMs of PKR ( $\left.\mathrm{PKR}_{1-169}\right)$ highlights that nearly the entire length of the protein tracks a curved path to form contacts with the RNA stem-loop, involving both dsRBMs and the linker that joins them (Fig. 6A). This is consistent with the observation that high-affinity binding to TAR requires both dsRBMs of PKR, and NMR chemical shift perturbation experiments that have identified the binding interface to involve both dsRBMs and the linker (Kim et al. 2006). A striking feature of the model is the apparent decrease in flexibility of TAR RNA upon interaction with $\mathrm{PKR}_{1-169}$ and the ability to visualize both the stem and loop portions of TAR RNA (Fig. 6A; Supplemental Fig. S1). Based on our modeling results of the free protein, we propose that dsRBM1 is responsible primarily for interaction with the loop, whereas the linker and dsRBM2 primarily interact with the stem region of TAR RNA. These results are supported by preliminary NMR data that indicate that site-specific spin-labeling of dsRBM2 broadens imino proton resonances in the stem region far from the loop region (Supplemental Fig. S2). The model also suggests that the C-terminal end of the protein (dsRBM2) may be oriented such that the 80-residue interdomain linker and kinase domain are not directly affected by interaction with the RNA; similar observations have been made previously (McKenna et al. 2007). The RNA sequesters the tandem dsRBMs entirely, which would preclude the RNA from interacting with another molecule of PKR or an interaction between the dsRBMs and kinase domains from a single PKR molecule.

While the model resolution is not sufficient to confirm the nucleotides involved, the observed TAR loop structure suggests that a region larger than the expected hexaloop may be involved in loop formation. The TAR RNA hexaloop is highly dynamic (Jaeger and Tinoco 1993) and has been shown to adopt significantly different conformations, depending on its association with ligands including small molecules, peptides, proteins, and other nucleic acid molecules (Bardaro et al. 2009; Fulle et al. 2010). Concerted motions in TAR RNA have been suggested as the basis for access to bound state conformations (Al-Hashimi et al. 2002). HIV-2 TAR undergoes similar conformational changes (Raghunathan et al. 2006). Other dsRBM-containing proteins such as Saccharomyces cerevisiae Rntlp (Wu et al. 2004) and Drosophila Staufen (Ramos et al. 2000) have shown a preference for loop regions, and mutation of the TAR hexaloop, bulge, or stem results in a significant reduction in binding affinity to PKR (Kim et al. 2006). Therefore, there is significant experimental basis for recognition of the TAR loop via the dsRBMs of PKR.

Our SAXS, DLS, and size exclusion chromatography data are all consistent with a 1:1 complex stoichiometry under the conditions in which the experiments were performed. With the experimentally determined hydrodynamic parameters, we were unable to fit the acquired scattering data to any other complex stoichiometry. These results are consistent with previous NMR experiments in which the same complex stoichiometry is observed (Kim et al. 2006; McKenna et al. 2007). It is important to stress that this study has been focused on a bound conformation of the PKR-TAR complex, and no comment can be made on whether this complex represents an active conformation. TAR RNA dimerization has been suggested as a potential mechanism required for activation (Heinicke et al. 2009), and while our data cannot preclude this possibility, it does not directly support it either.

We additionally examined a second viral dsRNA stemloop, $\mathrm{VA}_{\mathrm{I}}$-AS, in order to determine the generality of our results. Previously performed NMR experiments have indicated that identical amino acid residues in PKR are responsible for the interaction with both TAR and $\mathrm{VA}_{\mathrm{I}}-\mathrm{AS}$ and that similar regions of the stem-loop structure are responsible for interaction with PKR (McKenna et al. 2006). Free $\mathrm{VA}_{\mathrm{I}}$-AS is more conformationally constrained than TAR, and the same trend is observed once it is bound to $\mathrm{PKR}_{1-169}$, as $\mathrm{VA}_{\mathrm{I}}$-AS undergoes only moderate conformation changes (Figs. 5, 6) However, the SAXS envelope of TAR and $\mathrm{VA}_{\mathrm{I}^{-}}$ AS-containing complexes have similar overall domain orientations and hydrodynamic parameters, consistent with a similar mode of interaction supporting previous studies (McKenna et al. 2006).

Overall, the work presented demonstrates how tandem dsRBMs are capable of tolerating a wide range of sequence and structural motifs to function in the innate immune response to viral infection. A rigorous characterization of additional dsRNA ligands, and the full length protein, will help to resolve the full spectrum of interactions possible for the dsRBMs of PKR. 


\section{MATERIALS AND METHODS}

\section{PKR $_{1-169}$ expression and purification}

Recombinant human $\mathrm{PKR}_{1-169}$ protein was expressed and purified according to the method previously described (McKenna et al. 2006). Affinity purified protein was subjected to size exclusion chromatography using a HiLoad 26/60 Superdex 75 gel filtration column $(2.6 \times 60 \mathrm{~cm}$, GE Healthcare Life Sciences) in $50 \mathrm{mM}$ Tris $(\mathrm{pH}$ 7.50), $100 \mathrm{mM} \mathrm{NaCl}$, and $5 \mathrm{mM}$ 2-mercaptoethanol (2-Me). The elution fractions were monitored by means of absorbance at 280 $\mathrm{nm}$, and fractions containing purified protein were combined and concentrated using Millipore concentrator filters $\left(M_{W}\right.$ cut-off, 3000; Millipore). At all stages, protein purity is checked by SDSPAGE, and the concentration was determined using the known extinction coefficient measured by spectrophotometry (NanoDrop 2000c, Thermo Scientific).

\section{RNA preparation and purification}

HIV-1 TAR and adenovirus $\mathrm{VA}_{\mathrm{I}}$-AS RNA were in vitro transcribed from linearized template under control of the T7 RNA polymerase promoter and purified by gel filtration chromatography according to the method previously (McKenna et al. 2006). Purified RNA were subsequently concentrated using Millipore concentrator filters ( $M w$ cutoff, 3000; Millipore). The purity of the transcribed RNA was verified by native polyacrylamide gel electrophoresis (in $1 \times$ TBE buffer), and the concentration was determined by spectrophotometer.

\section{RNA-protein complex formation}

$\mathrm{PKR}_{1-169}-\mathrm{TAR}$ and $\mathrm{PKR}_{1-169}-\mathrm{VA}_{\mathrm{I}}$-AS complexes were prepared by incubating purified $\mathrm{PKR}_{1-169}$ in the presence excess RNA in a buffer containing $50 \mathrm{mM}$ Tris ( $\mathrm{pH} 7.50)$ and $100 \mathrm{mM} \mathrm{NaCl}$ for $15 \mathrm{~min}$ at room temperature. After incubation, the mixture was applied on a HiLoad 26/60 Superdex 75 gel filtration column $(2.6 \times 60 \mathrm{~cm}$, GE Healthcare Life Sciences). Elution fractions were assayed for the presence of RNA-protein complex via in-line spectrophotometer $(260 / 280 \mathrm{~nm}$ simultaneously) and were confirmed by native PAGE. Fractions containing RNA-protein complex were pooled and concentrated in Millipore concentrators ( $M w$ cut off, 3000; Millipore). The purity of both complexes was assessed by the native polyacrylamide gel electrophoresis, and the concentrations were determined spectrophotometrically using RNA extinction coefficients and assuming the complex had 1:1 stoichiometry. EMSAs were performed using native polyacrylamide gels as described previously (Booy et al. 2012), with the exception that samples were prepared in a different buffer (50 mM Tris at $\mathrm{pH} 7.50,100 \mathrm{mM} \mathrm{NaCl})$.

\section{Dynamic light scattering}

Prior to the examination by DLS, all samples were dialyzed for $2 \mathrm{~h}$ at $4^{\circ} \mathrm{C}$ against $50 \mathrm{mM}$ Tris ( $\mathrm{pH} 7.50$ ), $100 \mathrm{mM} \mathrm{NaCl}$. After dialysis, all the macromolecules were subjected to filtration through a $0.1-\mu \mathrm{m}$ filter (Millipore), and samples were equilibrated at $20^{\circ} \mathrm{C}$ prior to data acquisition. The hydrodynamic radius and homogeneity of each sample were examined using the Zetasizer Nano $S$ system (Malvern Instruments) equipped with a $4-\mathrm{mW}$ laser $(\lambda=633 \mathrm{~nm})$ according to the method previously described (Meng et al. 2012). The DLS experiments for each sample were performed at multiple concentrations: $2.50-6.50 \mathrm{mg} / \mathrm{mL}$ for $\mathrm{PKR}_{1-169}, 0.70-1.30 \mathrm{mg} / \mathrm{mL}$ for TAR, $0.80-1.90 \mathrm{mg} / \mathrm{mL}$ for $\mathrm{VA}_{\mathrm{I}}-\mathrm{AS}, 0.30-1.10 \mathrm{mg} / \mathrm{mL}$ for the $\mathrm{PKR}_{1-169}-\mathrm{TAR}$ complex, and $0.70-1.30 \mathrm{mg} / \mathrm{mL}$ for the $\mathrm{PKR}_{1-169}-$ $\mathrm{VA}_{\mathrm{I}}$-AS complex. DLS data were analyzed using DTS software (version 6.01, Malvern Instruments).

\section{Small angle X-ray scattering}

DLS data for $\mathrm{PKR}_{1-169}$, RNA, and $\mathrm{PKR}_{1-169}-\mathrm{RNA}$ complexes were collected prior to SAXS data collection to confirm that all the samples are highly pure and suitable for data collection. The SAXS data for TAR were collected at $0.7,1.0,1.3 \mathrm{mg} / \mathrm{mL}$; for $\mathrm{VA}_{\mathrm{I}}$-AS at 1.0 , 1.4 , and $1.9 \mathrm{mg} / \mathrm{mL}$; for $\mathrm{PKR}_{1-169}$ at $3.5,4.5$, and $5.5 \mathrm{mg} / \mathrm{mL}$; for $\mathrm{PKR}_{1-169}-\mathrm{TAR}$ complex at $0.80,1.20$, and $2.10 \mathrm{mg} / \mathrm{mL}$; and $\mathrm{PKR}_{1-169}-\mathrm{VA}_{\mathrm{I}}$-AS complex at $0.60,0.9$, and $1.63 \mathrm{mg} / \mathrm{mL}$ (all in $50 \mathrm{mM}$ Tris at $\mathrm{pH} 7.50,100 \mathrm{mM} \mathrm{NaCl}$ buffer). The data collection was performed on a Rigaku S-MAX3000 equipped with a Rigaku MicroMax+002 microfocus sealed tube $(\mathrm{Cu} \mathrm{Ka}$ radiation at 1.54 $\AA$ ) and a Confocal Max-Flux (CMF) optics system operating at $40 \mathrm{~W}$ (Rigaku). Scattering data were recorded using a 200-mm multiwire two-dimensional detector. The data for all three samples and buffer were collected for $3 \mathrm{~h}$ for each sample within the range of $0.008 \leq s \leq 0.26 \AA^{-1}$ and processed according to the method previously described, where $s=4 \pi \sin \theta / \lambda$ (Patel et al. 2010, 2011, 2012). Briefly, the sample data were subtracted from the buffer data using the program PRIMUS (Konarev et al. 2003) followed by merging of buffer subtracted data for each sample and the complex. The data were further processed using the GNOM program (Svergun 1992) to obtain radius of gyration $\left(r_{G}\right)$ and maximal particle dimension $\left(D_{\max }\right)$. The ab initio modeling for protein and individual RNA molecules was performed using the program DAMMIF (Franke and Svergun 2009). The program MONSA (Svergun 1999) was employed to calculate ab initio models of protein-RNA complexes by fitting data for protein, RNA, and the complex simultaneously. The quality of the models was verified by the goodness of fit parameter $(\chi$-value $)$ after each model calculation. Ab initio models for each sample and complex were then rotated and averaged using the program DAMAVER (Volkov and Svergun 2003) to obtain a representative conformation where the NSD parameter was used to determine the quality of superimposition of ab initio models.

The three-dimensional structures of $\mathrm{PKR}_{1-169}$ were calculated using the program BUNCH (Petoukhov and Svergun 2005), where high-resolution data from the PDB file 1QU6 (Nanduri et al. 1998) was used and fitted with the SAXS data. Both domains of $\mathrm{PKR}_{1-169}$ were allowed to rotate freely and find their optimized positions and orientations according to the method described previously (Patel et al. 2011, 2012). The quality of the models was checked by means of the determined $\chi$-value. To produce Figure 5B, individual bunch models were superimposed on average ab initio model using supcomb (version 2.0) (Kozin and Svergun 2001).

\section{Comparison of hydrodynamic properties}

The program HYDROPRO (de la Torre et al. 2000) was employed to calculate solution properties such as hydrodynamic radius, radius of gyration, and maximal particle dimension for each model calculated using SAXS data for $\mathrm{PKR}_{1-169}$, free RNA, and the $\mathrm{PKR}_{1-169}-\mathrm{RNA}$ 
complexes. The input parameters for HYDROPRO calculations included molecular weight, partial specific volume $(\bar{v})$, as well as density and viscosity of the buffer. A buffer density of $1.0038 \mathrm{~g} / \mathrm{mL}$ and a viscosity of 0.01026 Poise were calculated using the program SEDNTERP (Laue et al. 1992). The sequence molecular weight (18831.5) and partial specific volume $(0.738 \mathrm{~mL} / \mathrm{g})$ of $\mathrm{PKR}_{1-169}$ was calculated using the ProtParam utility available on the ExPaSy server and the SEDNTERP program, respectively. The sequence molecular weight for HIV-1 TAR (18354.4) and $\mathrm{VA}_{\mathrm{I}} \mathrm{-AS}$ (17165.6), as well as the partial specific volumes for HIV-1 TAR $(0.5689 \mathrm{~mL} / \mathrm{g})$, and $\mathrm{VA}_{\mathrm{I}}$-AS $(0.569 \mathrm{~mL} / \mathrm{g})$, were calculated using NucProt Calculator (Voss and Gerstein 2005). Additionally, the partial specific volume for the complex of $\mathrm{PKR}_{1-169^{-}} \mathrm{HIV}-1$ TAR as well as $\mathrm{PKR}_{1-169}-\mathrm{VA}_{\mathrm{I}}-\mathrm{AS}$ was calculated using Equation 1:

$$
\bar{v}_{\text {complex }}=\frac{\left(M_{\mathrm{PKR}} \bar{v}_{\mathrm{PKR}}+M_{\mathrm{RNA}} \bar{v}_{\mathrm{RNA}}\right)}{\left(M_{\mathrm{PKR}}+M_{\mathrm{RNA}}\right)} .
$$

\section{SUPPLEMENTAL MATERIAL}

Two supplemental figures are included in order to improve the quality and clarity of the manuscript. A description of the data is enclosed within the appropriate figure legend.

\section{ACKNOWLEDGMENTS}

We thank Drs. Michael Freund and Torsten Hegmann for providing access to SAXS instrumentation and Drs. Insil Kim and Jody Puglisi for providing NMR data in Supplemental Figure S2. Work was supported by both a Discovery Grant from the Natural Sciences and Engineering Research Council of Canada (NSERC) and an Operating Grant from the Manitoba Health Research Council (MHRC). E.D. was partially supported by the University of Manitoba GETS program. T.R.P. was supported by a CIHR Postdoctoral Fellowship. S.D. was supported by a University of Manitoba Faculty of Science Scholarship.

Received August 8, 2012; accepted December 12, 2012.

\section{REFERENCES}

Aboul-ela F, Karn J, Varani G. 1996. Structure of HIV-1 TAR RNA in the absence of ligands reveals a novel conformation of the trinucleotide bulge. Nucleic Acids Res 24: 3974-3981.

Al-Hashimi HM, Gosser Y, Gorin A, Hu W, Majumdar A, Patel DJ. 2002. Concerted motions in HIV-1 TAR RNA may allow access to bound state conformations: RNA dynamics from NMR residual dipolar couplings. J Mol Biol 315: 95-102.

Bardaro MF Jr, Shajani Z, Patora-Komisarska K, Robinson JA, Varani G. 2009. How binding of small molecule and peptide ligands to HIV-1 TAR alters the RNA motional landscape. Nucleic Acids Res 37: 1529-1540.

Benkirane M, Neuveut C, Chun RF, Smith SM, Samuel CE, Gatignol A, Jeang KT. 1997. Oncogenic potential of TAR RNA binding protein TRBP and its regulatory interaction with RNA-dependent protein kinase PKR. EMBO J 16: 611-624.

Berkhout B, Silverman RH, Jeang KT. 1989. Tat trans-activates the human immunodeficiency virus through a nascent RNA target. Cell 59: 273-282.

Bevilacqua PC, Cech TR. 1996. Minor-groove recognition of doublestranded RNA by the double-stranded RNA-binding domain from the RNA-activated protein kinase PKR. Biochemistry 35: 9983-9994. Booy EP, Meier M, Okun N, Novakowski SK, Xiong S, Stetefeld J, McKenna SA. 2012. The RNA helicase RHAU (DHX36) unwinds a G4-quadruplex in human telomerase RNA and promotes the formation of the P1 helix template boundary. Nucleic Acids Res 40: $4110-4124$.

Bycroft M, Grunert S, Murzin AG, Proctor M, St Johnston D. 1995. NMR solution structure of a dsRNA binding domain from Drosophila staufen protein reveals homology to the N-terminal domain of ribosomal protein S5. EMBO J 14: 3563-3571.

Carpick BW, Graziano V, Schneider D, Maitra RK, Lee X, Williams BR. 1997. Characterization of the solution complex between the interferon-induced, double-stranded RNA-activated protein kinase and HIV-I trans-activating region RNA. J Biol Chem 272: 9510-9516.

Dar AC, Dever TE, Sicheri F. 2005. Higher-order substrate recognition of eIF2 $\alpha$ by the RNA-dependent protein kinase PKR. Cell 122: 887-900.

de la Torre JG, Huertas ML, Carrasco B. 2000. Calculation of hydrodynamic properties of globular proteins from their atomic-level structure. Biophys J 78: 719-730.

Dimitrova DI, Yang X, Reichenbach NL, Karakasidis S, Sutton RE, Henderson EE, Rogers TJ, Suhadolnik RJ. 2005. Lentivirus-mediated transduction of PKR into CD $34^{+}$hematopoietic stem cells inhibits HIV-1 replication in differentiated T cell progeny. J Interferon Cytokine Res 25: 345-360.

Franke D, Svergun DI. 2009. DAMMIF, a program for rapid ab-initio shape determination in small-angle scattering. J Appl Crystallogr 42: 342-346.

Fulle S, Christ NA, Kestner E, Gohlke H. 2010. HIV-1 TAR RNA spontaneously undergoes relevant apo-to-holo conformational transitions in molecular dynamics and constrained geometrical simulations. J Chem Inf Model 50: 1489-1501.

Gabel F, Wang D, Madern D, Sadler A, Dayie K, Daryoush MZ, Schwahn D, Zaccai G, Lee X, Williams BR. 2006. Dynamic flexibility of double-stranded RNA activated PKR in solution. J Mol Biol 359: 610-623.

Gale M Jr, Katze MG. 1998. Molecular mechanisms of interferon resistance mediated by viral-directed inhibition of PKR, the interferoninduced protein kinase. Pharmacol Ther 78: 29-46.

Gan J, Tropea JE, Austin BP, Court DL, Waugh DS, Ji X. 2006. Structural insight into the mechanism of double-stranded RNA processing by ribonuclease III. Cell 124: 355-366.

Gunnery S, Green SR, Mathews MB. 1992. Tat-responsive region RNA of human immunodeficiency virus type 1 stimulates protein synthesis in vivo and in vitro: Relationship between structure and function. Proc Natl Acad Sci 89: 11557-11561.

Heinicke LA, Wong CJ, Lary J, Nallagatla SR, Diegelman-Parente A, Zheng X, Cole JL, Bevilacqua PC. 2009. RNA dimerization promotes PKR dimerization and activation. J Mol Biol 390: 319-338.

Hovanessian AG. 2007. On the discovery of interferon-inducible, double-stranded RNA activated enzymes: The $2^{\prime}-5^{\prime}$ oligoadenylate synthetases and the protein kinase PKR. Cytokine Growth Factor Rev 18: $351-361$.

Jaeger JA, Tinoco I Jr. 1993. An NMR study of the HIV-1 TAR element hairpin. Biochemistry 32: 12522-12530.

Kharrat A, Macias MJ, Gibson TJ, Nilges M, Pastore A. 1995. Structure of the dsRNA binding domain of E. coli RNase III. EMBO J 14: 3572-3584.

Kim I, Liu CW, Puglisi JD. 2006. Specific recognition of HIV TAR RNA by the dsRNA binding domains (dsRBD1-dsRBD2) of PKR. J Mol Biol 358: 430-442.

Konarev PV, Volkov VV, Sokolova AV, Koch MHJ, Svergun DI. 2003. PRIMUS: A Windows PC-based system for small-angle scattering data analysis. J Appl Cryst 36: 1227-1282.

Kozin MB, Svergun DI. 2001. Automated matching of high- and lowresolution structural models. J Appl Crystallogr 34: 33-41.

Laue TM, Shah BD, Ridgeway TM, Pelletier SL. 1992. Computer-aided interpretation of analytical sedimentation data for proteins. In Analytical ultracentrifugation in biochemistry and polymer science 
(ed. SE Harding et al.), pp. 90-125. Royal Society of Chemistry, Cambridge, UK.

Lemaire PA, Lary J, Cole JL. 2005. Mechanism of PKR activation: Dimerization and kinase activation in the absence of double-stranded RNA. J Mol Biol 345: 81-90.

Lemaire PA, Tessmer I, Craig R, Erie DA, Cole JL. 2006. Unactivated PKR exists in an open conformation capable of binding nucleotides. Biochemistry 45: 9074-9084.

Maitra RK, McMillan NA, Desai S, McSwiggen J, Hovanessian AG, Sen G, Williams BR, Silverman RH. 1994. HIV-1 TAR RNA has an intrinsic ability to activate interferon-inducible enzymes. Virology 204: 823-827.

Malmgaard L. 2004. Induction and regulation of IFNs during viral infections. J Interferon Cytokine Res 24: 439-454.

McKenna SA, Kim I, Liu CW, Puglisi JD. 2006. Uncoupling of RNA binding and PKR kinase activation by viral inhibitor RNAs. J Mol Biol 358: 1270-1285.

McKenna SA, Lindhout DA, Kim I, Liu CW, Gelev VM, Wagner G, Puglisi JD. 2007. Molecular framework for the activation of RNAdependent protein kinase. J Biol Chem 282: 11474-11486.

Meng H, Deo S, Xiong S, Dzananovic E, Donald LJ, van Dijk CW, McKenna SA. 2012. Regulation of the interferon-inducible $2^{\prime}-5^{\prime}$-oligoadenylate synthetases by adenovirus $\mathrm{VA}_{\mathrm{I}}$ RNA. J Mol Biol 422: 635-649.

Nallagatla SR, Bevilacqua PC. 2008. Nucleoside modifications modulate activation of the protein kinase PKR in an RNA structure-specific manner. RNA 14: 1201-1213.

Nallagatla SR, Hwang J, Toroney R, Zheng X, Cameron CE, Bevilacqua PC. 2007. 5'-triphosphate-dependent activation of PKR by RNAs with short stem-loops. Science 318: 1455-1458.

Nanduri S, Carpick BW, Yang Y, Williams BR, Qin J. 1998. Structure of the double-stranded RNA-binding domain of the protein kinase PKR reveals the molecular basis of its dsRNA-mediated activation. EMBO J 17: 5458-5465.

Patel TR, Morris GA, Zwolanek D, Keene DR, Li J, Harding SE, Koch M, Stetefeld J. 2010. Nano-structure of the laminin $\gamma$-1 short arm reveals an extended and curved multidomain assembly. Matrix Biol 29: 565-572.

Patel TR, Meier M, Li J, Morris G, Rowe AJ, Stetefeld J. 2011. T-shaped arrangement of the recombinant agrin G3-IgG Fc protein. Protein Sci 20: 931-940.

Patel TR, Reuten R, Xiong S, Meier M, Winzor DJ, Koch M, Stetefeld J. 2012. Determination of a molecular shape for netrin-4 from hydrodynamic and small angle X-ray scattering measurements. Matrix Biol 31: 135-140.

Petoukhov MV, Svergun DI. 2005. Global rigid body modeling of macromolecular complexes against small-angle scattering data. Biophys J 89: $1237-1250$.

Puglisi JD, Tan R, Calnan BJ, Frankel AD, Williamson JR. 1992. Conformation of the TAR RNA-arginine complex by NMR spectroscopy. Science 257: 76-80.

Puthenveetil S, Whitby L, Ren J, Kelnar K, Krebs JF, Beal PA. 2006. Controlling activation of the RNA-dependent protein kinase by siRNAs using site-specific chemical modification. Nucleic Acids Res 34: 4900-4911.
Raghunathan D, Sanchez-Pedregal VM, Junker J, Schwiegk C, Kalesse M, Kirschning A, Carlomagno T. 2006. TAR-RNA recognition by a novel cyclic aminoglycoside analogue. Nucleic Acids Res 34: 3599-3608.

Ramos A, Grunert S, Adams J, Micklem DR, Proctor MR, Freund S, Bycroft M, St Johnston D, Varani G. 2000. RNA recognition by a Staufen double-stranded RNA-binding domain. EMBO J 19: 997-1009.

Ryter JM, Schultz SC. 1998. Molecular basis of double-stranded RNAprotein interactions: Structure of a dsRNA-binding domain complexed with dsRNA. EMBO J 17: 7505-7513.

Sadler AJ, Williams BR. 2008. Interferon-inducible antiviral effectors. Nat Rev Immunol 8: 559-568.

Saunders LR, Barber GN. 2003. The dsRNA binding protein family: Critical roles, diverse cellular functions. FASEB J 17: 961-983.

SenGupta DN, Silverman RH. 1989. Activation of interferon-regulated, dsRNA-dependent enzymes by human immunodeficiency virus-1 leader RNA. Nucleic Acids Res 17: 969-978.

Sonenberg N, Hinnebusch AG. 2009. Regulation of translation initiation in eukaryotes: Mechanisms and biological targets. Cell 136: 731-745.

Stefl R, Oberstrass FC, Hood JL, Jourdan M, Zimmermann M, Skrisovska L, Maris C, Peng L, Hofr C, Emeson RB, et al. 2010. The solution structure of the ADAR2 dsRBM-RNA complex reveals a sequence-specific readout of the minor groove. Cell 143: 225-237.

Sudhakar A, Ramachandran A, Ghosh S, Hasnain SE, Kaufman RJ, Ramaiah KV. 2000. Phosphorylation of serine 51 in initiation factor $2 \alpha($ IF $2 \alpha)$ promotes complex formation between eIF $2 \alpha(P)$ and eIF2B and causes inhibition in the guanine nucleotide exchange activity of eIF2B. Biochemistry 39: 12929-12938.

Svergun DI. 1992. Determination of the regularization parameter in indirect-transform methods using perceptual criteria. J Appl Crystallogr 25: 495-503.

Svergun DI. 1999. Restoring low resolution structure of biological macromolecules from solution scattering using simulated annealing. Biophys J 76: 2879-2886.

Thomis DC, Samuel CE. 1993. Mechanism of interferon action: Evidence for intermolecular autophosphorylation and autoactivation of the interferon-induced, RNA-dependent protein kinase PKR. J Virol 67: 7695-7700.

VanOudenhove J, Anderson E, Krueger S, Cole JL. 2009. Analysis of PKR structure by small-angle scattering. J Mol Biol 387: 910-920.

Volkov VV, Svergun DI. 2003. Uniqueness of ab initio shape determination in small-angle scattering. J Appl Crystallogr 36: 860-864.

Voss NR, Gerstein M. 2005. Calculation of standard atomic volumes for RNA and comparison with proteins: RNA is packed more tightly. $J$ Mol Biol 346: 477-492.

Weber F, Wagner V, Rasmussen SB, Hartmann R, Paludan SR. 2006. Double-stranded RNA is produced by positive-strand RNA viruses and DNA viruses but not in detectable amounts by negative-strand RNA viruses. J Virol 80: 5059-5064.

Wu H, Henras A, Chanfreau G, Feigon J. 2004. Structural basis for recognition of the AGNN tetraloop RNA fold by the double-stranded RNA-binding domain of Rntlp RNase III. Proc Natl Acad Sci 101: 8307-8312. 

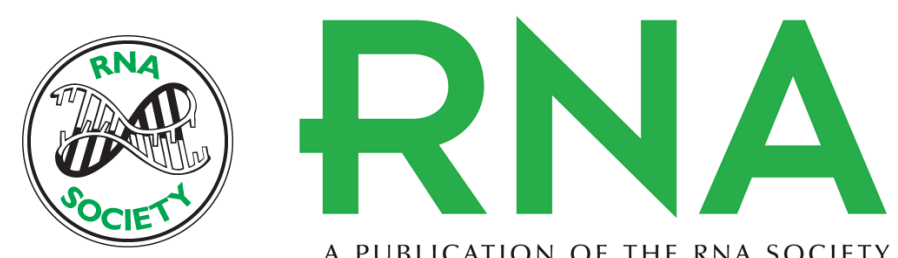

A PUBLICATION OF THE RNA SOCIETY

\section{Recognition of viral RNA stem-loops by the tandem double-stranded RNA binding domains of PKR}

Edis Dzananovic, Trushar R. Patel, Soumya Deo, et al.

RNA 2013 19: 333-344 originally published online January 17, 2013

Access the most recent version at doi:10.1261/rna.035931.112

\section{Supplemental http://rnajournal.cshlp.org/content/suppl/2013/01/04/rna.035931.112.DC1 \\ Material}

References This article cites 58 articles, 13 of which can be accessed free at:

http://rnajournal.cshlp.org/content/19/3/333.full.html\#ref-list-1

\section{License}

Email Alerting Receive free email alerts when new articles cite this article - sign up in the box at the Service top right corner of the article or click here.

\section{||I||||| Providing Precise Solutions for your research.}

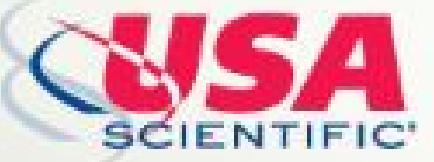

To subscribe to $R N A$ go to:

http://rnajournal.cshlp.org/subscriptions 